\section{References}

BENJAMIN, S., HOUSE, A. \& JENKINS, P. (1994) Liaison Psychiatry. Defining Needs and Planning Services. London: Gaskell.

BURLINSON, S. \& GUTHRIE, E. (2001) Senior house officer training in liaison psychiatry - are College guidelines being implemented? Psychiatric Bulletin, 25, 191-193.

CREED, F., MAYOU, R. \& HOPKINS, A. (1992) Medical Symptoms not Explained by Organic Disease. London: Royal College of Psychiatrists \& Royal College of Physicians of London.

GUTHRIE, E. (1998) Development of liaison psychiatry. Real expansion or a bubble that is about to burst? Psychiatric Bulletin, 22, 291-293.

— \& CREED, E. (1996) Seminars in Liaison Psychiatry. London: Gaskell.

HOUSE, A. \& CREED, F. (1993) Training in liaison psychiatry. Recommendations from the Liaison Psychiatry Group Executive Committee. Psychiatric Bulletin, 17,95-96.
-, MAYOU, R. \& MALLINSON, C (1995) Psychiatric Aspects of Physica Disease. London: Royal College of Physicians \& Royal College of Psychiatrists.

MAYOU, R. \& LLOYD, G. (1985) A survey of liaison psychiatry in the United Kingdom and Eire. Bulletin of the Royal College of Psychiatrists, 9, 214-217.

—, AITKEN, C., CONNOLLY, J., et al (1982) A College group for liaison psychiatry? Bulletin of the Royal College of Psychiatrists, 6, 143-144.

-, ANDERSON, H., FEINMANN, C., et al (1990) The present state of consultation and liaison psychiatry. Psychiatric Bulletin, 14, 321-325.

PEVELER, R., FELDMAN, E. \& FRIEDMAN T. (2000) Liaison Psychiatry. Planning Services for Specialist Settings. London: Gaskell.

ROYAL COLLEGE OF PHYSICIANS \& ROYAL COLLEGE OF PSYCHIATRIST

(1995) The Psychological Care of Medical Patients. Recognition of Need and Service Provision. Council Report R35. London: Royal College of Physicians \& Royal College of sychiatrists.

— \& - (1995) The Psychological Care of Medical Patients. A Guide for

Purchasers. Council Report CR38. ondon: Royal College of Physicians \& Royal College of Psychiatrists.

—, - \& ROYAL COLLEGE OF GENERAL PRACTITIONERS (1996) Chronic Fatigue Syndrome. Report of a Joint Working Group of The Royal Colleges of Physicians, Psychiatrists and General Practitioners. Council Report CR54. London: Royal College of Physicians, Royal College of Psychiatrists \& Roya College of General Practitioners.

ROYAL COLLEGE OF PSYCHIATRISTS (1994) The General Hospital Management of Adult Deliberate Selfharm. A Consensus Statement on Standards of Service Provision. Counci Report CR32. London: Royal College of Psychiatrists.

Geoffrey G. Lloyd Liaison Psychiatry Section Executive Committee, Consultant Liaison Psychiatrist, Royal Free Hospital, Pond Street, London NW3 2 OE
- (1996) Psychiatric Services to Accident and Emergency Departments. Report of a Joint Working Party of the Royal College of Psychiatrists and the British Association for Accident and Emergency Medicine. Council Report CR43. London: Royal College of Psychiatrists.

ROYAL COLLEGE OF SURGEONS OF ENGLAND \& ROYAL COLLEGE OF PSYCHIATRISTS (1997) Report of the Working Party on the Psychological Care of Surgical Patients. Council Report CR55. London: Royal College of Surgeons of England \& Royal College of Psychiatrists.

SHARPE, M., GUTHRIE, E., PEVELER, R et al (1996) The psychological care of medical patients: a challenge for undergraduate medical education. Journal of The Royal College of Physicians of London, 30, 202-204

\title{
Treading the skies: David Goldberg
}

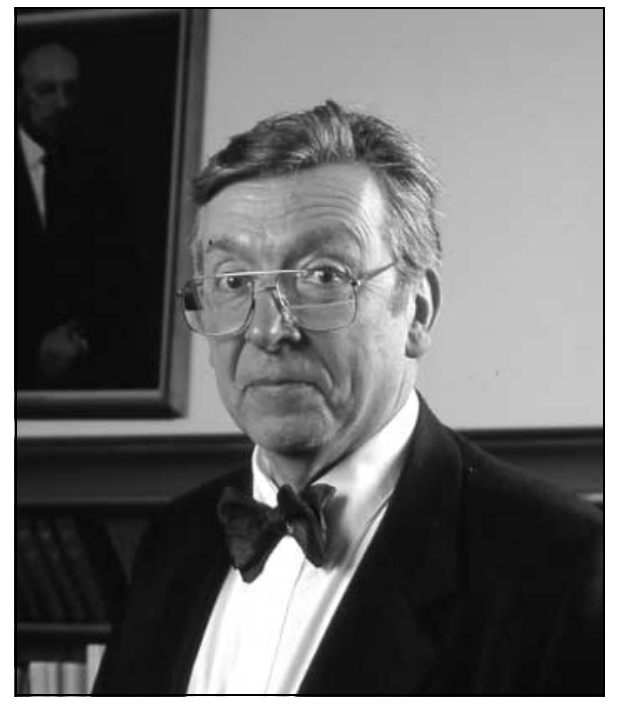

David Goldberg

This interview was carried out in a restaurant in the South of Naples with the backdrop of Mount Vesuvius and Pompeii to the South and the Bay of Naples to the West. I think that this was an appropriate setting to set in context the contribution of probably the most important influence on social psychiatry in the past 30 years. It is an

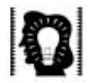

special articles
David Goldberg was educated at William Ellis School and Hertford College, Oxford. He took a degree in psychology and went on to do his clinical work at StThomas' Hospital. After house jobs at the National Hospital, Queen Square and the Brompton Hospital he studied psychiatry under Sir Aubrey Lewis at the Maudsley. He developed the General Health Questionnaire as a DPM project, and developed it further for his DM degree. After leaving the Institute he spent a year in Philadelphia before returning to Manchester as a senior lecturer. In 1972 he was appointed Professor and Head of Department at Manchester and spent the next 20 years building up the Department. He is an exponent of a bio-social model for common mental disorders, and has written books dealing with both epidemiological aspects of psychiatry and straightforward textbooks. He returned to the Maudsley in 1993 as Professor of Psychiatry and Director of Research and Development, and was knighted in 1997. He became a Professor Emeritus of King's College London in 2000 influence that extends far beyond the shores of these islands and will be recognised immediately by all those who go to international conferences and hear his work mentioned with reverence. David, if present, will always do his best to be suitably irreverent in his own contributions, but no one can doubt his immense achievements in 
both research and education to the international psychiatric community. I hope this interview gives the flavour of the man and his work at a time when his life is moving into a different, but we trust, highly productive phase.

David, what first interested you in psychiatry? Were there any important family influences?

No, none at all. I wanted to be a psychiatrist before I knew what a psychiatrist was and I had a list of things I wanted to do when I was a sixth former, which had psychiatry at the top, with biophysics next and then anything with combinations of biophysics and science, but I had not the slightest idea of what a psychiatrist was when I made that young decision to be one.

\section{Didn't your father have an impact?}

Yes. He insisted on me training as a doctor. I wanted to train as a psychologist when I was an undergraduate and he only allowed me to read psychology at Oxford if I also read medicine. My father was the civil servant in charge of government training centres and industrial rehabilitation units after the war. When these had finished with exservicemen, they turned their attention to mental hospital patients. As a schoolboy, I followed my father's work in this unfamiliar field with great interest. He noted that psychologists, mainly industrial psychologists at that time, tended to have a chip on their shoulders about not being medically qualified. He therefore suggested that if I insisted on being a psychologist then I should train as a doctor. I have never regretted that. I never thought that I'd need to be a doctor but it's been a very good profession for me. My father only lived to see me qualify and he saw me write my first prize essay, which was about rehabilitation, and he was quite pleased to see that.

\section{Where were you trained medically?}

I trained at Oxford University Medical School and then I did my clinical work at St Thomas' in London.

\section{Who were the major influences on you at StThomas'}

I think that Evan Jones, a Welsh physician, a very intuitive person, was the most important influence on me. And I also had very nice, scientific evidence-based medicine taught to me by Brian Creamer, a physician, and Dennis Cottom, a paediatrician who was also quite important to me in letting me know that you didn't have to be inarticulate, Welsh and intuitive to be a good doctor.

\section{Did William Sargant, who was at StThomas'at that time,} have an influence on you?

Yes, he had a very interesting influence on me because I naturally attended every one of his ward rounds during my training. But I was more impressed by his assistant, a Jewish psychiatrist called Dr Shorvon; he had a much more brilliant mind. He was almost the Evan Jones of Psychiatry because he had an uncanny intuitive insight into patients' motivations, which fascinated me in my time as a medical student, whereas William was always a more establishment figure who said things which I listened to but was not necessarily impressed by.

\section{Where did you go after leaving St Thomas'?}

I did the rounds. I went to the National Queen Square and then the Brompton. Then I came back to St Thomas' for some time as a medical registrar and finally decided I'd had enough and went to the Maudsley in 1963.

What were your impressions of the Maudsley at that time?

Oh, I found it a magnificent place to go to because it was like going back to university. St Thomas' had been an amazing, fascinating, supportive and pleasant place to do my training but it was not an academic setting, and, going to the Maudsley was like going back to Oxford. Not only was it so exciting going there but I liked the fact that almost without exception everyone of my contemporaries was obsessed with food.

\section{In what way?}

They were literally obsessed; a journey for them round England was from one Good Food Guide restaurant to another. I remember on my first day at the Maudsley I didn't know anybody and I was reading a paper in which there was a recipe for crème brûlée. I said to the chap next to me, who had started on the same morning, 'I don't make crème brûlée like this'. This remark completely stopped all conversation in the junior common room. Everybody put their newspapers down and before we had finished I had nine different recipes for crème brûlée.

When you arrived at the Maudsley, Aubrey Lewis was pre-eminent. What influence did he have on you?

A very decisive influence. He was the most scholarly psychiatrist I have ever met. It was him that persuaded me that my adolescent fantasies about psychiatry were probably correct and that I was prepared to give my life to doing this. If I hadn't read his paper 'Between doubt and certainty in psychiatry' in the Lancet while I was a medical student I would never have persisted with my wish to be a psychiatrist. And I found Aubrey even more impressive to meet than he had been to read.

\section{Who else were decisive figures at your time in the Maudsley?}

Few will remember him but Jack Dewsbury, my first consultant, but he was an important influence on me. Jack was a man who didn't make contact with people very easily but his knowledge of human frailty was considerable. He was extremely good in putting references in front of me and suggesting things for me to read, and he gave me a knowledge of pornography that I would never have had had I not worked for him. Heinz Wolff was also important because he gave me the 
confidence to talk to patients and to try to understand their dilemmas. Many of the consultants at the Maudsley at the time were not really very interested in whether you had a constructive discussion with patients and Heinz Wolff gave me enough confidence to do that. I had psychotherapy supervision from Heinz for about 5 years during my training and found that very useful. The other person who was enormously important to me was Douglas Bennett, who believed in "giving a service for sick people", a phrase which I remembered constantly. He looked after all the patients that the Maudsley had rejected and those in the day hospital were an amazing collection of people who had failed psychiatric treatment in the other units at the Maudsley. I learnt there to do something for them and this was very important too.

Was this the time you first decided you would go into social psychiatry?

No, I don't think so because I made this decision at Oxford before I went into psychiatry, before I even read medicine. I had been a psychologist, and that gave me a basis in approaching psychological problems in a statistical way. It was almost inevitable that I would be a social psychiatrist because of the methods of approaching the subject that I learnt as a psychologist at Oxford.

You have written quite often in the past about Michael Shepherd and his work. How much did he influence you during your time at the Maudsley?

Well, he was an interesting influence. I remember first stopping him in the car park and saying I wanted to work for him; he almost fell over with astonishment. A few months later I found that I was indeed working with him and at times I found this a more difficult experience than I had thought possible. Sometimes I simply couldn't stay awake in his ward rounds because his manner with patients was so unpleasant that I found consciousness was no longer possible. I learnt to stick closely beside him and go into a deep delta sleep during these ward rounds but he never looked at me and so I think I was never discovered. It was during this time that I started my research and told him that I thought that psychiatry needed a screening questionnaire. To my surprise he agreed with this suggestion and he arranged a series of supervision sessions with his subordinates, Brian Cooper and Henry Kedward. I found these so frustrating that I used to throw all my notes in a rage into a basket that I kept in my study and refused to look at them for at least 2 to 3 weeks after my supervision sessions. But I eventually learnt to get over my anger and pick my notes up again and before long I had found that I'd spent my time in research as a trainee designing the General Health Questionnaire. When I subsequently returned to Michael and worked for him as a research worker we had a completely different relationship and I no longer felt the need to go to sleep in his presence.

The General Health Questionnaire (GHQ) was published as a Maudsley Monograph in 1972 and has probably been the most significant screening instrument in epidemiological psychiatry. Have you been surprised by the influence of the GHQ and its successes in different forms over the years.

Absolutely. One of the things that used to make me angry when I was a young registrar was that Michael would wonder at the impossibility of designing a screening questionnaire. He thought it would be impossible to design a questionnaire that applied to everyone - at one time he suggested that perhaps I should be designing a questionnaire for red-headed female clerks in Croydon. I remember that that was one of the occasions when I threw my notes into the basket and thought of something else for a few weeks. So subsequently I was amazed when the questionnaire not only worked in Croydon but also, a few years later, astonished to find that it worked equally well in a completely different cultural setting in the United States. This was certainly not what my teachers had led me to expect. I had been told to suppose that you had to get absolutely into the nuances of a culture in order to design a screening questionnaire.

More recently I have learned that so far from this being true the questionnaire works equally well in 15 very different cities, provided you make an adjustment for differences in prevalence in each place.

You were appointed to a senior lecturer position in Manchester at the end of the 1960s. Why did you choose to go to Manchester?

I didn't choose to go to Manchester. Michael Shepherd suggested that there was a job there that I might like to apply for and I anxiously went around to people I respected at the Maudsley, such as Michael Rutter and Julian Leff, asking whether I should do that. None of them made the slightest attempt to delay me and Michael Shepherd had me into his office, where there was an extremely uncomfortable chair that he chose for a person to be interviewed, and said that if I went to Manchester that I could come back from the United States and I would "have something which was yours". For some odd reason, he pronounced the last word 'youers' and this stuck in my mind. I decided that there was nothing for me to lose. It seemed a good idea to get a job in England before I left for the United States and so I applied for the post and got it. In Philadelphia I gained my first experience of 'community psychiatry', and carried out a survey using the GHQ in a new culture. It was there that I first began to use the GHQ to study doctors.

After going to Manchester you were there for 24 years. They were very productive ones.

Yes. I went there when Neil Kessell was only the second professor of psychiatry that the University of Manchester had had. We worked together very well. He was an important colleague who taught me to work the university system in a way that nobody at the Maudsley had taught me to do. I owe him a debt of gratitude because he taught me how to handle a committee and how to get my own way in the university. 


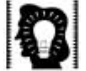

special articles
At that time Manchester was, and still is I suppose, well outside the golden triangle of influence in research. How did you find the research potential in Manchester and how did you respond to it?

Nobody was doing any research at all in Manchester when I got there. The idea of funded research was completely foreign to the department. Friendliness was the main quality that characterised people in the department and even that could be qualified in certain respects. It was necessary to produce an atmosphere in which people would do research and to attract people who were capable of research. It took me a long time to achieve this, and, looking back, I feel I should have done it more quickly than I did. But in those days the importance of research was not taken for granted in the British university system and I was surprised at how many timeservers there were, not just in the Faculty of Medicine, but in the University as a whole. At that time the university system was full of people who once appointed did no more research and just sat in their jobs, took long vacations when it suited them, and were generally unproductive. I have to say, that the Research Assessment Exercise, of which I know that many people, including yourself, are critical, was a much needed change in the British university system.

Shortly after going to Manchester you became involved with work with the Royal College. How did this develop?

Well, it developed because I volunteered and was appointed to the Research Committee. But, looking back, it was really a rather dismal experience in the early days of a new committee. We wanted a number of things but none of which we achieved. For example, we wanted a research component in the membership examinations, which was subsequently granted, but at the time we proposed it, it was regarded as absurd and it was voted down. We also wanted the College to do two pieces of research. One was on the efficacy of psychotherapy and the availability of psychotherapy in the NHS, and the other on the therapeutic effects of psychosurgery. Jim Watson and I, who worked together on the Research Committee, thought that only the College could do this work because of its wide membership and the good reputation it had among British psychiatrists. But unfortunately we were completely thwarted. The only research that the College did, after almost a year of inconsequential wrangling on the Research Committee, was initiated by Martin Roth, who was then the president, who came to one of our meetings one day and said the College wished to do research on ECT. And so it was; that is the research the College did and I left in disgust shortly afterwards.

You are known by most of us in psychiatry as a great educator. Where does the influence in education come from? Was that there right from the very beginning?

The work I did with Bob Hobson, where we worked out a model for teaching psychotherapy to trainee psychiatrists, was very much based on my early experience at the Maudsley. There I felt that over 5 years in training I had learnt to do certain things with patients but these were learnt painfully on the job and nobody had told me what it was I was meant to be doing. It seemed perfectly possible to stipulate what these things were and then to teach them. I well remember that, together with Bob and Peter Maguire, we produced a set of learning video-tapes. My impression at this time was that Britain had 20 medical schools and at least 10 of them were totally opposed to talking to patients at all. They seemed to want to keep the patient as a biological organism and interfere with its neurotransmitters so I thought that if we sold nine sets of videos we would be lucky. We actually sold 300 sets in the first month and I realised we were on to something big, and that teaching was something that people take quite seriously.

You subsequently became Chairman of the General and Old Age PsychiatryAdvisory Committee (GOAPSAC) and had an influence on the training of psychiatrists in the United Kingdom. Would you like to describe your experiences of that?

At that time the higher training committee tended to either approve or disapprove a scheme without making evaluative comments about individual teachers. And, because they were chary of this they tended to approve everything that was put to them and the first round of inspections resulted in 100\% approval. I thought this was ridiculous and it was likely that there were good and bad posts in any place and that the role of the General and Old Age Psychiatry Advisory Committee was not only to identify people who were good trainers but also to identify posts that were not useful for training. We had to allow a scheme to develop but ensure that we dropped placements that weren't good for the trainees. I think that the changes that I introduced early to GOAPSAC have been followed by others.

It was while you were at Manchester that you developed your model of psychiatric services that is now commonly called the filter model. I wonder if you could tell us how this developed.

Well, it developed because there were two halves to my life that were not connected. There was epidemiology, which produced rates of prevalence in the normal population and there were the hospital statistics from the Department of Health which produced rates of out-patient and in-patient care, and there was Michael Shepherd's 1-year study of mental health in primary care that gave what is now level three of conspicuous morbidity in the model. The work I had done in developing the screening questionnaire for Michael made me believe that there was another level in addition to the two levels of official statistics. This was the level of mental morbidity among people who are seeking medical care (which has now become level two). The reason why they hadn't been brought together was because the epidemiological surveys at level one were all point 
prevalence and the data from levels four and five from official statistics were annual rates. So I converted the population rates to annual period prevalence rates and that required me to understand the inception rates of illness as well as their point prevalence. At the time there was very little known about the inception rates of common disorders and I had to do a lot of guessing. In the first book I wrote in 1980 with Peter Huxley we made a clean breast of it and admitted what we'd had to guess. In the second book we were able to quote much better data and to show that we weren't very far out in the estimates we had made of inception rates for common disorders. Thus we were able to bring together the five levels using annual period prevalence rates for each level.

In your work you have collaborated with many others from different disciplines and could be described as a very good multi-disciplinary researcher. Would you like to comment about your liaison and cooperation with different disciplines and their influence on you during the course of your career?

Well, I think it started off with my training as a psychologist before I became a doctor. I have always found psychologists to be my natural allies and the people that I most admire in terms of their approach to scientific problems. It has therefore never been difficult for me to work with them. My time working for the London MRCP examination as a physician led me to have many good relationships with British physicians and I found it very easy when I was working in a general hospital to work with the professors of medicine and surgery and others in that way too. During my time in Manchester I began to develop liaisons with economists in order to do the first health economic studies in British psychiatry. These were first done with Norman Glass whom I met at the Department of Health Committee, and later with several other health economists who were just beginning to work out the methodologies for evaluating the old services. The other people that I've worked with closely have been statisticians and among these the most impressive was undoubtedly Paul Duncan-Jones, a mathematical psychologist. I found his approach to problems intensely illuminating and a decisive influence on my life.

You returned to the Maudsley as Professor of Psychiatry, Director of Medical Services and Director of Research and Development in 1993. Can you describe the Maudsley at that time and the tasks you set yourself?

Yes, I thought that I would be hated for it seemed perfectly ridiculous for one person should be given all these hats to wear, but to my amazement people both tolerated and received me in a very friendly way. It was good that they did for at the time the Maudsley had its back against the wall with powerful and determined enemies in the regional health authority and the Department of Health. They saw no point in ivy league, ivory towered mental hospitals and were quite happy to see the Maudsley destroyed. As soon as I arrived I decided my main task was to persuade people in the Health
Department that we had a main role in researching issues for the National Health Service.

In 1994 Science Watch, in Philadelphia, pronounced the Institute of Psychiatry one of the most effective and productive research organisations in the world. It must have been a great pleasure to you.

Yes. We were the most cited medical research institution and in the top 20 there were no other institutions outside North America. So, eat your heart out, Hammersmith Hospital, you didn't make it. But this was not my work. I accept no credit whatsoever for that achievement. It was the achievement of the colleagues who were working at the Maudsley and whose work gave real value. It was an immense shot in the arm for the organisation and within 24 hours of that report being published, the Secretary of State was quoting it in public. I realised then we had made a quantum leap in terms of our public image.

David, you have always placed yourself clearly in the spectrum of social psychiatry and this covers a broad range of disciplines. Do you think social psychiatry is in good shape at present or is it under threat?

I think it is under severe threat. In fact, I'm not even sure if it is going to survive much into the next millennium. Community psychiatry and epidemiology, which in the past were seen as components of social psychiatry, have now taken off in their own right, and it isn't clear to me that there are new heirs to the throne of social psychiatry.

If I could just move to your personal life, David. Many will know of the important work of your wife, Ilfra, in her work supporting flexible training in psychiatry. Fewer will know that you have two sisters-in-law with close connections to psychiatric colleagues. How did this all happen?

The three girls, Ilfra, Diana and Deborah were daughters of a headmaster whom I knew well. He was a very warm, interesting but rather an authoritarian man and he always used to tell his daughters that the one sort of person who he couldn't abide at any price was a psychiatrist. They obviously were impressed by this advice because each one married someone who either was already a fairly dedicated psychiatrist or was to become one very soon. All three girls are now married to professors of psychiatry. I am the husband of the eldest, lan Brockington is the husband of the second and Tim Harding, the professor of legal medicine in Geneva is the husband of the third. We get on together very well and I don't think we have had to work at that.

\section{What influence has Ilfra had on your professional career}

Well, an enormous influence; more than I can say really. She has humanised me and she calms my tendency to paranoia when my colleagues infuriate me. Everything I have achieved I owe to her really. She is the basis of the stability that I have, of the happiness I have known in my 
(8)

special articles life, and it has been the most marvellous marriage for me. She was the Assistant Postgraduate Dean in Manchester before she moved to London and there she had a wider brief because she looked after the houseman year as well as the flexible trainees. In London she deals with a much larger area and I think has made a great impact on the pattern of postgraduate training in England in the last few years.

It is hard to believe that you are now retired as you have been such a dynamo over the years and active in all parts of psychiatry. How are you going to spend your retirement?

Well, I have got an enormous amount to do. People keep making offers that I can't refuse so that I am beginning to wonder whether I am going to get any time to relax in at all. I am designing training materials for general practitioners and training materials for psychiatrists to train them in neuropsychiatric skills. I have also assisted in the production of a computerised treatment package for anxiety and depression. All these things need to be evaluated and assessed and I am going to Italy and to Australia next year where I hope to do trials of the training materials that I have produced. I am doing some work for the Office of Science and Technology on future technological needs in neuropsychiatry and I have got a book to write. What with one thing and another and various people wanting me to go and give lectures, life is as busy now as it's ever been.

I know in recent years you have made a number of bleak predictions about the possible future of our mental health services. I wonder now how you think things are going to go in the next few years?

Well, I think that the community mental health movement is a very healthy one for patients and I think that the practice of looking after people in a normal, domestic environment rather than in an institution is absolutely correct. Unfortunately, the conditions of today's National Health Service for young psychiatrists leave a great dea to be desired and it doesn't surprise me that consultant posts, particularly in deprived inner-cities, are very difficult to fill. I think that the rot began with the Griffiths Report - before that, when things went wrong in the health service we were able to blame people above us in the power hierarchy; ultimately, anger was directed at the Secretary of State. Now blame has been devolved downwards and one searches for scapegoats and victims who are the most junior and defenceless people in the mental health service. And, naturally, junior doctors are in the firing line and feel themselves to be so and life only becomes marginally better for them when they get the consultant contracts. So, I think that the high levels of sickness absence and burnout in the mental health professions is a factor which disturbs me a great deal and I have yet to hear any plan by a government to really take that seriously or do anything to address. I think that the National Service Framework, which is the most recent development, is in a way desirable, but like so many other things won't be resourced properly and will be used as a weapon to attack people. It's part of the culture of blame, the culture of criticism and diminution of people's efforts. I would much prefer to be part of a system where people were praised for their achievements and given positive rewards rather than all stick and no carrot.

How do you think the profession as a whole ought to be tackling this? Should this be through the Royal College, should it be through the BMA, or should it be by direct action? Do you think we ought to be quietly trying to oppose this or have you any other solution for us?

Well, I think that the College is the most obvious place where there should be some action and I am very conscious that in my professional lifetime our profession hasn't taken a very radical attitude when things have been done to the mental health service that have damaged it. I think when, for example, psychiatric social workers were taken away from hospital and put into local authority employment it was actually a very bad day for mental health services and we didn't even complain as a College. And, I think that I would like to see the College being very much more positive in trying to improve the conditions that young psychiatrists have to work in.

David, do you think that young people will continue to want to work in psychiatry

Yes, they definitely will. Advances in neuropsychiatry are extremely exciting, and the brain is a far more complex organ than the heart - which is basically just a pump. We can now do more for patients than ever before, and there are treatments for conditions which were virtually untreatable when I started off. We have an assured future because our work is intrinsically both challenging and very rewarding. 